\title{
Utilization of Insecticide Treated Nets and Health Seeking Behavior for fever among Children under Five in Southwest Nigeria
}

\section{Melford Esuabom ( $\nabla$ esuabommelford@gmail.com )}

University of Ibadan College of Medicine https://orcid.org/0000-0001-6632-9093

\section{Mabel Kamweli Aworh}

African Field Epidemiology Network

Chukwuma David Umeokonkwo

AFENET: African Field Epidemiology Network

Muhammad Shakir Balogun

AFENET: African Field Epidemiology Network

\section{Eniola Bamgboye}

University of Ibadan College of Medicine

\section{Tukur Dahiru}

Ahmadu Bello University Teaching Hospital

\section{Research}

Keywords: Malaria, Insecticide-treated nets, Children under-5, Health seeking behavior, Southwest Nigeria, Nigeria Demographic Health Survey

Posted Date: November 22nd, 2021

DOI: https://doi.org/10.21203/rs.3.rs-1079937/v1

License: (9) This work is licensed under a Creative Commons Attribution 4.0 International License.

Read Full License 


\section{Abstract}

\section{Background}

Malaria remains a burden globally with the WHO African region accounting for $94 \%$ of the overall disease burden and deaths in 2019. Nigeria alone accounted for $27 \%$ of total malarial cases and $23 \%$ of deaths. Insecticide-treated nets (ITN) use and receiving early care for fever represent the most cost-effective means of malaria prevention and control. In this study, we assessed the utilization of ITNs in households with under-five children in Southwest Nigeria, the health-seeking behavior of their caregivers for fever, and associated factors.

Methods

This was a secondary data analysis of the 2018 Nigeria Demographic and Health Survey. Analysis was restricted to under-five children residing in Southwest Nigeria. Multivariate analysis using logistic regression was conducted to determine factors associated with utilization of ITNs and care-seeking for fever in under-five children. Complex samples command of SPSS (Version 23) was used to account for survey sampling design.

Results

Of 2,281 under-five children in households with at least one ITN, 67.6\% (1542) slept under an ITN the night before the survey. Predictors of ITN use were the age of child ( $<12$ months), wealth index (poorest), number of nets in a household ( 2 or more), and number of household members (1-3). Of the 4,153 underfive children, $8.7 \%$ (360) had fever, and advice or treatment was sought for $72.4 \%$ (261). Predictors of good health-seeking behavior were the age of a child $<12$ months $(A O R=2.81,95 \% \mathrm{Cl}=1.08-7.31)$, mothers' education, and state of residence. Mothers who had secondary education were less likely to report care-seeking than those with higher education ( $A O R=0.43,95 \% \mathrm{Cl}=0.19-0.98$ ). Mothers from Osun, Ekiti, and Lagos state were less likely to seek care than those from Ogun state.

Conclusion

We found that the utilization of insecticide-treated nets and seeking of care for fever in under five years of age in Southwest Nigeria were below the National Malaria Strategic Plan goal of $80 \%$ and $100 \%$ respectively. The state governments of Osun, Ekiti, and Lagos should develop strategies to improve ITN use and early seeking of care for fever in under-five children.

\section{Background}

Malaria is an infectious disease caused by species of the protozoan parasite, Plasmodium (predominantly P. falciparum) and, transmitted by Anopheles mosquitoes. Globally, there were an estimated 227 million cases of malaria in 87 malaria-endemic countries and an estimated 407,000 people died from malaria in 2019(1). Malaria is the third leading cause of death in children under five 
years old (U5) years worldwide, after pneumonia and diarrheal disease, and accounts for almost one out of five deaths in children less than 5 years(2). The proportion of total malaria deaths among children U5 was $67 \%$ in $2019(1)$.

The prevalence of malaria is highest in sub-Saharan Africa, which accounted for $94 \%$ of cases totaling about 215 million cases in 2019(1). Nigeria (27\%), the Republic of the Congo (12\%), Uganda (5\%), Mozambique (4\%), and Niger (3\%) accounted for $51 \%$ of all cases globally(1). Sub-Saharan Africa also accounted for $94 \%(384,000)$ of malaria deaths. Nigeria alone accounted for almost $23 \%$ of malarial deaths globally(1). In 2009, the Nigerian Federal Ministry of Health estimated that malaria was a direct contributor to $11 \%$ of overall maternal mortality, $25 \%$ of infant mortality, and $30 \%$ of under-five mortality. Children in regions of steady transmission are at increased risk of progression to severe disease compared to adults(3). Malaria also contributes to malnutrition in children, which indirectly leads to the death of half of all children under the age of five throughout the world(4)(5). Southwest Nigeria has the highest malaria prevalence in children under 5 (U5) (50.3\%) according to a previous study(6). However, the 2015 Malaria Indicator Survey (MIS) and the 2018 Nigeria Demographic Health Survey (NDHS) reported a prevalence of $32.1 \%$ and $28.9 \%$ respectively(7)(8).

Nigeria has implemented 4 national malaria strategic plans (NMSP) to date. The fourth NMSP (20142020) aimed to achieve pre-elimination status and reduce malaria-related deaths to zero by 2020 . Two objectives of this plan were to provide at least $80 \%$ of the targeted population with appropriate preventive measures and to treat all individuals with confirmed malaria in the appropriate health facilities and with effective antimalarial medicines(7). Preventive measures to be implemented include sustained mass distribution of long-lasting insecticide nets (LLIN). Insecticide-treated nets have been established to prevent malaria by reducing the number of infective bites by mosquitoes. ITNs are cost-effective and evidence suggests that they result in a $44 \%$ reduction in the incidence of severe malaria episodes in persons who used ITNs compared to those who did not according to a systematic review(9).

Effective malaria case management is important for preventing morbidity and mortality among children under five. This includes seeking early treatment (within 24 hours) at a health facility. In this study, we analyzed data to assess the utilization of ITNs among children U5 in the Southwest region of Nigeria and factors associated with the use of ITNs, health-seeking behavior of caregivers for fever in children U5, and associated factors.

\section{Methods}

\section{Study Design}

We conducted secondary data analysis on the data set obtained from the 2018 Nigerian Demographic Health Survey (NDHS 2018). The 2018 NDHS is a nationally representative survey conducted by the National Population Commission (NPC). ICF International provided technical assistance through the DHS program which is funded by the United States Agency for International Development (USAID). Other 
agencies were involved in providing technical and financial support for the successful implementation of the survey.

\section{Study Setting}

Southwest Nigeria is one of the 6 geopolitical zones in Nigeria comprising of the following states: Ekiti, Lagos, Osun, Ondo, Ogun, and Oyo. The area lies between longitude $2^{0} 3^{1}$ and $6^{0} 00^{1} \mathrm{E}$ and latitude $6^{0} 2^{1}$ and $8^{0} 37^{1} \mathrm{~N}$ with a total land area of $77,818 \mathrm{~km}^{2}$. It has 2 distinct seasons which are the rainy season (April-October) and the dry season (November-March). The predominant language spoken in the region is Yoruba. However, several other ethnic groups exist. The population in Southwest is estimated to be $27,511,892$ based on the NPC Census of 2006 (10). The majority of the occupants are farmers, traders, artisans, etc.

\section{Study Population}

The study focused on children U5 who were de facto members of households that owned at least 1 ITN in Southwest, Nigeria. Furthermore, a subset of children U5 who had a fever in the 2 weeks before the survey was also studied.

\section{Data Collection}

The 2018 NDHS was conducted from August to December 2018. The sampling frame used for the survey was the Population and Housing Census of the Federal Republic of Nigeria (NPHC) which was conducted by the NPC in 2006. The sampling for the survey was done using a stratified sampling method conducted in 2 stages. Stratification was achieved by dividing the 36 states and the Federal Capital territory into 2 strata: urban and rural. A total of 41,668 households were selected for the sample, of which 40,666 were occupied. Of the occupied households, 40,427 were successfully interviewed, yielding a response rate of $99 \%$. Women aged 15-49 years old were interviewed in selected households and the women's questionnaire included questions related to children in these households. We obtained household ownership of at least one ITN by merging the Household member recode (PR) and the Household Recode (HR) data set. We further extracted data from the merged data set for children U5 who were de facto members of households that owned at least 1 ITN in Southwest Nigeria and had slept in the house the night before the survey. This resulted in a total of 1,887 children or 2,281 after applying sample weights. Assessment of health-seeking behavior for fever in children U5 was done using the children recode (KR) data set. We first extracted data on children U5 living in Southwest Nigeria, resulting in a weighted count of 4,153 , and then extracted data on children who had fever 2 weeks before the survey. This resulted in a total of 322 children or 360 after applying sample weights.

\section{Data Analysis}

Analysis was conducted using SPSS (version 23.0). The dependent variable for net utilization was whether a child U5 slept under an ITN the night before the survey in households that had at least 1 ITN. 
The dependent variable for fever health-seeking behavior was whether a caregiver of a child U5 who had a fever within the past 2 weeks preceding the survey sought advice or treatment. This includes those who sought advice or treatment from the following sources: public sector, private medical sector, shop, market, itinerant drug seller, and community-oriented resource person. We excluded advice or treatment from traditional practitioners. Independent variables for net use were classified as child and household factors. Child factors included the age and gender of a child. Household factors were type of place of residence, wealth index, age of household head, gender of household head, number of nets in a household, number of de facto household members, and state of residence. In addition to child and household factors, maternal factors were included as independent variables for fever health-seeking behavior. This includes women's age group, religion, highest education level, literacy level, and marital status. Descriptive statistics were conducted on dependent and independent variables. Chi-square was used to test the association between child factors, maternal factors, household factors, and outcome variables. The level of significance was set at $5 \%$ and $10 \%$ for ITN use and seeking advice or treatment of fever respectively. Multivariate analysis was done using logistic regression to test the strength of association between the independent and dependent variables at a 95\% confidence interval. The Complex Samples analysis method was used to account for the sampling technique and weighting factor applied in the survey. Results are presented as tables and figures.

\section{Results}

\section{Description of Sample Characteristics and utilization of nets for children U5}

Table 1 is a description of sample characteristics of children U5 in households with at least one ITN in southwest Nigeria. The majority of children in this study were within the age group 12-35 months (41.3\%, $\mathrm{n}=942)$ and $36-59$ months $(40.3 \%, \mathrm{n}=918)$. About half of the children were males $(51.7 \%, \mathrm{n}=1,179)$ and a majority were urban residents $(72.7 \%, n=1,659)$. The majority of children lived in households classified as rich under the wealth index $(44.5 \%, \mathrm{n}=1016)$. The proportion of households with males as heads of the household was higher than that of females $(85 \%, n=1,940)$. The highest proportion of children were from Lagos $(24.9 \% ; n=568)$ and Oyo state $(23.9 \%, n=544), n=522)$. Half of the children were from households that had only one ITN $(50.2 \%, n=1146)$. The majority of children were from households with between 4 to 6 household members $(65.6 \%, n=1497)$. About one-third of the children slept under an ITN the night before the survey $(67.6 \%, n=1542$, Table 1$)$. 
Table 1

Description of sample characteristics and utilization of net by children U5 $(n=2281)$

\begin{tabular}{|c|c|c|}
\hline Variable & Frequency & Proportion (\%) \\
\hline \multicolumn{3}{|c|}{ Child factors $(n=2,281)$} \\
\hline \multicolumn{3}{|c|}{ Age (in months) } \\
\hline$<12$ & 421 & 18.4 \\
\hline $12-35$ & 942 & 41.3 \\
\hline $36-59$ & 918 & 40.3 \\
\hline \multicolumn{3}{|l|}{ Gender } \\
\hline Male & 1,179 & 51.7 \\
\hline Female & 1,102 & 48.3 \\
\hline \multicolumn{3}{|c|}{ Household factors } \\
\hline \multicolumn{3}{|c|}{ Type of place of Residence } \\
\hline Urban & 1,659 & 72.7 \\
\hline Rural & 622 & 27.3 \\
\hline \multicolumn{3}{|c|}{ Gender of household head } \\
\hline Male & 1,940 & 85.0 \\
\hline Female & 341 & 15.0 \\
\hline \multicolumn{3}{|c|}{ Age of household head (in years) } \\
\hline$<29$ & 225 & 9.8 \\
\hline $29-49$ & 1,640 & 71.9 \\
\hline$\geq 50$ & 416 & 18.2 \\
\hline \multicolumn{3}{|c|}{ Wealth Index } \\
\hline Poorest & 69 & 3.0 \\
\hline Poorest & 172 & 7.6 \\
\hline Middle & 396 & 17.3 \\
\hline Richer & 629 & 27.6 \\
\hline Richest & 1,016 & 44.5 \\
\hline
\end{tabular}

Number of mosquito nets 


\begin{tabular}{|lll|}
\hline Variable & Frequency & Proportion (\%) \\
\hline 1 & 1,146 & 50.2 \\
\hline$\geq 2$ & 1,135 & 49.8 \\
\hline Number of household members & & \\
\hline $1-3$ & 418 & 18.3 \\
\hline $4-6$ & 1,497 & 65.6 \\
\hline$\geq 7$ & 367 & 16.1 \\
\hline State of residence & & \\
\hline Oyo & 544 & 23.9 \\
\hline Osun & 294 & 12.9 \\
\hline Ekiti & 151 & 6.6 \\
\hline Ondo & 341 & 15.0 \\
\hline Lagos & 568 & 24.9 \\
\hline Ogun & 383 & 16.8 \\
\hline Utilization of ITN by children U5 in households with at least one ITN & \\
\hline Child slept under an ITN the night before the survey & \\
\hline Yes & 1,542 & 67.6 \\
\hline No & 739 & 32.4 \\
\hline
\end{tabular}

\section{Factors Associated with Children U5 Sleeping Under Insecticide Treated Nets}

Table 2 is a summary of the association between dependent variables (child factors and household factors) and the utilization of ITN. Type of place of residence, wealth index, state of residence, age of a child, number of nets in a household, age of household head, and number of household members were associated with children U5 sleeping under ITNs $(p<0.05)$. Table 3 is a summary of the results of multivariate analysis showing the adjusted odds ratios (AORs). Age of child, wealth index, number of nets in households, number of household members, and state of residence were significantly associated with children sleeping under ITNs $(p<0.05)$. Children less than 12 months were more likely to sleep under ITN than those aged 36-59 months ( $\mathrm{AOR}=1.79, \mathrm{Cl}=1.33-2.41, \mathrm{p}=0.001)$. Children from households classified poorest were more likely to sleep under an ITN than those from the richest households $(A O R=2.60, \mathrm{Cl}=$ 1.15-5.90, $p=0.022$ ). Having more than one net was positively associated with children sleeping under $\operatorname{ITN}(\mathrm{AOR}=1.64, \mathrm{Cl}=1.17-2.30, \mathrm{p}=0.004)$. Children from households with 1-3 members $(\mathrm{AOR}=2.29, \mathrm{Cl}=$ $1.45-3.63, p=0.001)$ and $4-6$ members $(A O R=1.50, C l=1.04-2.15, p=0.03)$ were more likely to sleep under 
an ITN than children from households with 7 and above members. Children from Osun $(\mathrm{AOR}=0.49, \mathrm{Cl}=$ 0.27-0.87, $\mathrm{p}=-0.016)$, Ekiti ( $\mathrm{AOR}=0.34, \mathrm{Cl}=0.19-0.60, \mathrm{p}=0.001)$ and Lagos states $(\mathrm{AOR}=0.49, \mathrm{Cl}=0.26$ $0.90, p=0.022)$ were less likely to sleep under an ITN than those from Ogun State 
Table 2

Factors associated with ITN use in children U5 in Southwest Nigeria $(n=2,281)$

Variable

\begin{tabular}{|c|c|c|c|}
\hline \multirow[t]{2}{*}{ Variable } & \multicolumn{2}{|c|}{ Child slept under ITN } & \multirow[t]{2}{*}{$\mathrm{p}$ value } \\
\hline & Yes & No & \\
\hline & Freq (\%) & Freq (\%) & \\
\hline \multicolumn{4}{|c|}{ Child factors } \\
\hline \multicolumn{4}{|c|}{ Age (in months) } \\
\hline$<12$ & $320(76.0)$ & $101(24.0)$ & 0.001 \\
\hline $12-35$ & $642(68.1)$ & $300(31.9)$ & \\
\hline $36-59$ & $581(63.2)$ & $337(36.8)$ & \\
\hline \multicolumn{4}{|l|}{ Gender } \\
\hline Male & $800(67.9)$ & $379(32.1)$ & 0.812 \\
\hline Female & $742(67.3)$ & $360(32.7)$ & \\
\hline \multicolumn{4}{|c|}{ Household factors } \\
\hline \multicolumn{4}{|c|}{ Type of place of residence } \\
\hline Urban & 1078(65.0) & $581(30.0)$ & 0.005 \\
\hline Rural & $464(74.7)$ & $158(25.3)$ & \\
\hline \multicolumn{4}{|c|}{ Gender of Household head } \\
\hline Male & 1314(67.7) & $626(32.3)$ & 0.838 \\
\hline Female & $228(67.0)$ & 113(33.0) & \\
\hline \multicolumn{4}{|c|}{ Age of household head } \\
\hline$<29$ & 177(78.5) & $48(21.5)$ & 0.021 \\
\hline $29-49$ & 1094(67.6) & $546(33.3)$ & \\
\hline$\geq 50$ & $272(65.4)$ & $144(34.6)$ & \\
\hline \multicolumn{4}{|c|}{ Wealth index } \\
\hline Poorest & $56(80.6)$ & 13(19.4) & 0.008 \\
\hline Poorer & $126(73.0)$ & $46(27.0)$ & \\
\hline Middle & $268(67.8)$ & $128(32.2)$ & \\
\hline Richer & 461(73.3) & $168(26.4)$ & \\
\hline
\end{tabular}




\begin{tabular}{|llll|}
\hline Variable & \multicolumn{2}{l}{ Child slept under ITN value } & \\
\hline Richest & $632(62.2)$ & $384(37.8)$ & \\
\hline Number of mosquito nets & & & \\
\hline 1 & $724(63.2)$ & $422(36.8)$ & 0.008 \\
\hline 2 & $818(72.1)$ & $317(27.9)$ & \\
\hline Number of household members & & & \\
\hline $1-3$ & $317(76.0)$ & $101(24.0)$ & 0.005 \\
\hline $4-6$ & $1004(67.1)$ & $493(32.9)$ & \\
$\geq 7$ & $221(60.1)$ & $146(39.9)$ & \\
\hline State of residence & & & \\
\hline Oyo & & $124(22.7)$ & 0.001 \\
\hline Osun & $420(77.3)$ & $109(37.0)$ & \\
\hline Ekiti & $185(63.0)$ & $70(46.4)$ & \\
\hline Ondo & $81(53.6)$ & $105(30.7)$ & \\
\hline Lagos & $236(69.3)$ & $249(43.9)$ & \\
\hline Ogun & $319(56.1)$ & $82(21.6)$ & \\
\hline
\end{tabular}


Table 3

Multivariate analysis of factors associated with the use of ITN in children U5

\begin{tabular}{|c|c|c|}
\hline Variable & AOR & $95 \% \mathrm{Cl}$ \\
\hline \multicolumn{3}{|c|}{ Age of child (in months) } \\
\hline $36-59$ & 1.00 & \\
\hline$<12$ & 1.79 & $1.33-2.41$ \\
\hline $12-35$ & 1.22 & $0.94-1.59$ \\
\hline \multicolumn{3}{|c|}{ Type of place of residence } \\
\hline Urban & 1.00 & \\
\hline Rural & 1.12 & $0.80-1.56$ \\
\hline \multicolumn{3}{|c|}{ Age of Household head } \\
\hline$\geq 50$ & 1.00 & \\
\hline$<29$ & 1.56 & $0.87-2.80$ \\
\hline $29-49$ & 1.14 & $0.83-1.57$ \\
\hline \multicolumn{3}{|c|}{ Wealth index } \\
\hline Richest & 1.00 & \\
\hline Poorest & 2.60 & $1.15-5.90$ \\
\hline Poorer & 1.46 & $0.78-2.70$ \\
\hline Middle & 1.27 & $0.81-1.98$ \\
\hline Richer & 1.53 & $0.97-2.41$ \\
\hline \multicolumn{3}{|c|}{ Number of mosquito nets } \\
\hline 1 & 1.00 & \\
\hline$\geq 2$ & 1.64 & $1.17-2.30$ \\
\hline \multicolumn{3}{|c|}{ Number of household members } \\
\hline$\geq 7$ & 1.00 & \\
\hline $1-3$ & 2.29 & $1.45-3.63$ \\
\hline $4-6$ & 1.50 & $1.04-2.15$ \\
\hline \multicolumn{3}{|c|}{ State of residence } \\
\hline Ogun & 1.00 & \\
\hline
\end{tabular}




\begin{tabular}{|lll}
\hline Variable & AOR & $95 \% \mathrm{Cl}$ \\
\hline Oyo & 1.05 & $0.60-1.83$ \\
\hline Osun & 0.49 & $0.27-0.87$ \\
\hline Ekiti & 0.34 & $0.19-0.60$ \\
\hline Ondo & 0.58 & $0.31-1.07$ \\
\hline Lagos & 0.49 & $0.26-0.90$ \\
\hline
\end{tabular}

\section{Health seeking behavior of caregivers in Southwest Nigeria for fever in Children U5}

Table 4 is a summary of the health-seeking behavior of caregivers of children U5 who had a fever within 2 weeks preceding the survey. Figure 1 is a summary of where treatment was first sought for children U5 with fever. Of the 4,153 children in Southwest Nigeria, 8.7\%, $(n=360)$ had a fever in the last 2 weeks preceding the survey. Of these, advice or treatment for fever was sought for $72.4 \%(n=261)$. The proportion of children for whom advice or treatment was sought for the same day or the next was $43.6 \%$. More than a quarter of respondents $(27.6 \%, n=60)$ took their children to government health centers, while $17.7 \%(n=53)$ took their children to chemists/private medical stores. Table 5 is the result of bivariate analysis of independent variables of seeking advice or treatment for fever in children U5. Factors associated with seeking advice or treatment for fever were the age of the child, literacy level of the mother, highest educational level, sex of household head, wealth index, and state of residence $(p<0.1)$. Table 6 is the result of multivariate analysis of factors associated with seeking advice or treatment for fever in children U5. Age of child, the religion of caregiver, and mother's educational level were associated with seeking advice or treatment for fever $(p<0.05)$. Caregivers of children less than 12 months old and within 12-36 months were more likely to seek advice or treatment for fever than caregivers of children aged 36-59 months $(\mathrm{aOR}=2.81, \mathrm{Cl}=1.08-7.31, \mathrm{p}=0.034$ and $\mathrm{aOR}=1.86, \mathrm{Cl}=1.02-3.39, \mathrm{p}=0.042)$. Muslim caregivers were more likely to seek advice or treatment for fever than Christians $(\mathrm{aOR}=2.56, \mathrm{Cl}=1.30$ 5.03). Caregivers with secondary school education were less likely to seek care than those with higher education $(\mathrm{aOR}=0.43, \mathrm{Cl}=0.19-0.98, \mathrm{p}=0.045)$. Mothers from Osun state $(\mathrm{aOR}=0.06, \mathrm{Cl}=0.01-0.52)$, Ekiti state $(\mathrm{aOR}=0.09, \mathrm{Cl}=0.01-0.71)$, and Lagos state $(\mathrm{aOR}=0.11, \mathrm{Cl}=0.01-0.92)$ were less likely to seek care than those from Ogun state. 
Table 4

Health seeking behavior of caregivers in southwest Nigeria for fever in children U5

\begin{tabular}{|ll|}
\hline Variable & Frequency (\%) \\
\hline Child had fever in last 2 weeks $(\mathbf{n}=\mathbf{4 1 5 3})$ & $3776(90.9)$ \\
\hline No & $360(8.7)$ \\
\hline Yes & $16(0.4)$ \\
\hline Don't know & \\
\hline Child received treatment for fever $(\mathbf{n}=360)$ & $261(72.4)$ \\
\hline Yes & $100(27.6)$ \\
\hline No & \\
\hline Number of days after fever began sought treatment $(\mathbf{n}=360)$ & $157(43.6)$ \\
\hline Same-day or next & $101(28.0)$ \\
\hline $2-4$ & $102(28.3)$ \\
\hline$>5$ & \\
\hline
\end{tabular}


Table 5

Factors associated with seeking advice or treatment for fever in children U5 in Southwest Nigeria

Variable

Child factors

Age (in months)

$>12$

$12-35$

$36-59$

Gender

Male

Female

Maternal factors

Age

$15-24$

25-34

$>35$

\section{Education}

No education

Primary

Secondary

Higher

\section{Religion}

Christian

Islam

Current Marital status

Single, divorced, widow

Married/living with partner

Total Sought advice/treatment p value

\begin{tabular}{ll} 
Yes & No \\
\hline Freq (\%) & Freq (\%) \\
\hline
\end{tabular}

360

$\begin{array}{llll}51 & 43(83.2) & 8(16.8) & 0.065 \\ 174 & 130(74.7) & 44(25.3) & \\ 135 & 88(65.3) & 47(34.7) & \end{array}$

$186 \quad 138(74.2) \quad 38(25.8)$

0.405

$175 \quad$ 123(70.4) 52(29.6)

$50 \quad 40(80.5) \quad 10(19.5) \quad 0.109$

$186 \quad 141(75.8) \quad 45(24.2)$

$124 \quad 79(63.9) \quad 45(36.1)$

$23 \quad 13(57.8) \quad 10(42.2)$

$55 \quad 36(65.8) \quad 19(34.2)$

$217 \quad 155(71.3) \quad 62(28.7)$

$66 \quad 57(86.6) \quad 9((13.4)$

$\begin{array}{llll}217 & 147(67.8) & 70(32.2) & 0.038 \\ 143 & 114(79.4) & 29(20.6) & \end{array}$

$\begin{array}{llll}21 & 13(60.3) & 8(39.7) & 0.278 \\ 340 & 248(73.1) & 92(26.9) & \end{array}$




\begin{tabular}{|c|c|c|c|c|}
\hline Variable & Total & \multicolumn{2}{|c|}{ Sought advice/treatment } & $\mathrm{p}$ value \\
\hline \multicolumn{5}{|l|}{ Literacy } \\
\hline Cannot read at all & 70 & $36(52.1)$ & $34(47.9)$ & 0.001 \\
\hline Can read part or whole sentences & 291 & $225(77.2)$ & $66(22.8)$ & \\
\hline \multicolumn{5}{|l|}{ Household factors } \\
\hline \multicolumn{5}{|l|}{ Type of place of residence } \\
\hline Urban & 269 & 198(73.7) & $71(26.3)$ & 0.354 \\
\hline Rural & 91 & $62(68.3)$ & $29(31.7)$ & \\
\hline \multicolumn{5}{|l|}{ Wealth Index } \\
\hline Poorest & 18 & 11(59.7) & $7(40.3)$ & 0.004 \\
\hline Poorer & 41 & $24(58.0)$ & $17(42.0)$ & \\
\hline Middle & 58 & $31(53.8)$ & $27(46.2)$ & \\
\hline Richer & 100 & $75(74.9)$ & $25(25.1)$ & \\
\hline Richest & 143 & $120(83.8)$ & 23(16.2) & \\
\hline \multicolumn{5}{|l|}{ Number of household members } \\
\hline $1-3$ & 85 & $67(79.1)$ & 18(20.9) & 0.313 \\
\hline $4-6$ & 227 & $159(70.0)$ & $68(30.0)$ & \\
\hline$\geq 7$ & 48 & $34(71.5)$ & $14(28.5)$ & \\
\hline \multicolumn{5}{|l|}{ Gender of household head } \\
\hline Male & 301 & $224(74.5)$ & $77(25.5)$ & 0.094 \\
\hline Female & 59 & $36(61.7)$ & 23(38.3) & \\
\hline \multicolumn{5}{|l|}{ Age of household head } \\
\hline$<29$ & 34 & $25(73.0)$ & $9(23.0)$ & 0.937 \\
\hline $29-49$ & 274 & 197(71.9) & $77(28.1)$ & \\
\hline$>50$ & 53 & $39(74.4)$ & $14(25.6)$ & \\
\hline \multicolumn{5}{|l|}{ State of Residence } \\
\hline Oyo & 60 & $49(80.8)$ & 11(19.2) & 0.023 \\
\hline Osun & 72 & $47(65.8)$ & $25(34.2)$ & \\
\hline Ekiti & 53 & $32(60.4)$ & 21(39.6) & \\
\hline
\end{tabular}




\begin{tabular}{|llll|}
\hline Variable & Total & Sought advice/treatment & p value \\
\hline Ondo & 50 & $31(61.0)$ & $19(39.0)$ \\
\hline Lagos & 97 & $76(78.4)$ & $21(21.6)$ \\
\hline Ogun & 28 & $26(93.4)$ & $2(6.6)$ \\
\hline
\end{tabular}


Table 6

Multivariate analysis of factors associated with seeking advice or treatment for fever in children U5 in Southwest Nigeria

\begin{tabular}{|c|c|c|}
\hline Variable & AOR & $95 \% \mathrm{Cl}$ \\
\hline \multicolumn{3}{|l|}{ Age of child (in months) } \\
\hline $36-59$ & 1.00 & \\
\hline$<12$ & 2.81 & $1.08-7.31$ \\
\hline $12-35$ & 1.86 & $1.02-3.39$ \\
\hline \multicolumn{3}{|l|}{ Religion } \\
\hline Christian & 1.00 & \\
\hline Islam & 2.56 & $1.30-5.03$ \\
\hline \multicolumn{3}{|l|}{ Literacy } \\
\hline Can read part or whole & 1.00 & \\
\hline Cannot read at all & 0.31 & $0.08-1.08$ \\
\hline \multicolumn{3}{|l|}{ Mother's education } \\
\hline Higher & 1.00 & \\
\hline No education & 0.39 & $0.05-3.20$ \\
\hline Primary & 0.80 & $0.23-2.86$ \\
\hline Secondary & 0.43 & $0.19-0.98$ \\
\hline \multicolumn{3}{|c|}{ Gender of household head } \\
\hline Female & 1.00 & \\
\hline Male & 1.59 & $0.75-3.36$ \\
\hline \multicolumn{3}{|l|}{ Wealth index } \\
\hline Richest & 1.00 & \\
\hline Poorest & 0.49 & $0.10-2.53$ \\
\hline Poorer & 0.47 & $0.16-1.37$ \\
\hline Middle & 0.39 & $0.15-1.00$ \\
\hline Richer & 0.91 & $0.41-2.03$ \\
\hline
\end{tabular}




\begin{tabular}{|lll|}
\hline Variable & AOR & $95 \% \mathrm{Cl}$ \\
\hline Ogun & 1.00 & \\
\hline Oyo & 0.17 & $0.02-1.39$ \\
\hline Osun & 0.06 & $0.01-0.52$ \\
\hline Ekiti & 0.09 & $0.01-0.71$ \\
\hline Ondo & 0.09 & $0.01-1.00$ \\
\hline Lagos & 0.11 & $0.01-0.92$ \\
\hline
\end{tabular}

\section{Discussion}

In this study, utilization of ITN for children U5 was above average. This could be due to the mass distribution of nets during campaigns and antenatal visits combined with continuous education of caregivers during hospital visits on the need for bed net use by children U5 as a preventive measure for malaria. This should lead to a reduction in cases of malaria among children U5 in the region. This is similar to findings from previous studies in Osun State (58.3\%) and Southwest Nigeria (67.5\%), but higher than that reported in a study in Calabar in Nigeria where only $25 \%$ of children U5 slept under bed nets(11) (6)(12). This result is also similar to that in a study in the Niger Delta zone where $61.3 \%$ of children slept under bed nets(13). More importantly, this is higher than that reported in the 2015 NMIS report (39.2\%), indicating an increase in the utilization of ITNs by children U5(7). However, utilization by children U5 in southwest Nigeria was lower than the NMSP target of $80 \%(7)$.

Predictors of utilization of ITNs for children U5 were the age of a child, state of residence, number of nets in a household, and number of household members. Children aged 35 months and below were more likely to sleep under an ITN than older children. This is consistent with findings from other studies in Myanmar and Malawi(14)(15). Children within this age group are more likely to sleep with their parents thus making it more likely for the child to sleep under an ITN. Children in households with a higher number of nets were more likely to sleep under an ITN than those with a single net. This implies that the more nets a household possesses, the more likely it is for children U5 to sleep under ITNs. Children in households with fewer members were more likely to sleep under an ITN than children in households with more members. This is similar to findings in a previous study in Nigeria and Ethiopia(16)(17). There was no statistically significant association between type of place of residence and children U5 sleeping under an ITN. However, the proportion of children who slept under an ITN was higher in rural than urban settings. Children from households within the poorest wealth index were more likely to sleep under an ITN than children than those from households within the richest wealth index. This may be due to rich households being located in well-developed areas of states and the feeling of safety from mosquitoes by respondents. Association between caregivers' socioeconomic status and use of bed nets by children under five was also reported in a study in Ebonyi, Southeast Nigeria(18). In another study, children from 
wealthier households were more likely to use the nets than children from poorer households in Tanzania and Uganda(19). The WHO World Malaria Report 2020 indicated that ITN use was generally pro-poor or close to a perfect equality in West African Countries(1).

The majority (74.4\%) of caregivers who reported that children U5 had a fever in the last 2 weeks, sought treatment for the fever. This is similar to findings from a previous study in Northern Nigeria $(76.7 \%)$ and higher than that obtained in studies in Kaduna State, Nigeria, the Democratic Republic of the Congo, Myanmar, and Mozambique(66.7\%) (14)(20)(21)(22)(23). This finding is however lower than the $100 \%$ target of the NMSP(24). Also, government health facilities and private medical stores were the places most caregivers sought treatment when children U5 had a fever. The utilization of government and private health facilities should be encouraged as it fulfills a core objective of the NMSP(24). This finding is similar to that obtained in a study in Northern Nigeria and Ethiopia(21)(25). Previous studies among caregivers of children U5 also revealed that most caregivers seek treatment from private medical stores(21)(25). This could be due to the presence of these stores in great numbers in communities of developing countries. The utilization of government and private health facilities should be encouraged as it is one of the objectives of the NMSP. Less than half of the respondents sought treatment for children with a fever the same day or next. This is similar to the findings in a study in Ethiopia which reported only $38.7 \%$ of children received treatment within $24 \mathrm{hrs}$ of fever onset(25). Age of child, caregivers' religion, and education were predictors of seeking advice or treatment for fever. Seeking treatment was higher for children less than 12 months old than children aged 36-59 months. This is similar to findings from a study in Burkina Faso(26). A study in Myanmar revealed that seeking treatment or advice for treatment was higher for children $<36$ months than older children. This may be due to caregivers perceived severity of fever in younger children compared to older children. Odds of seeking advice or treatment was higher in Muslim caregivers than Christian caregivers. Caregivers with higher education were more likely to seek care than those with secondary education. This is contrary to findings in a previous study in Mozambique where caregivers with higher education were less likely to seek care(23). Mothers of children from Osun, Ekiti and Lagos were less likely to seek care than those from Ogun state.

This study was a cross-sectional study. Thus, a causal relationship could not be established between dependent and independent variables. The survey responses could also be affected by social desirability bias and recall bias as women were asked questions on net use the previous night and fever in children within 2 weeks preceding the survey. Nevertheless, the results of this study revealed important findings that could help future policy planning.

\section{Conclusion}

This study showed that utilization of ITN and seeking care for fever in children U5 in Southwest Nigeria was below the national targets. The governments of Osun, Ekiti, and Lagos should develop and implement strategies to improve net use and health-seeking behavior for children U5.

\section{Abbreviations}


AOR: Adjusted Odds Ratio, Cl: Confidence Interval, ITN: Insecticide-treated nets, U5: Under 5, NDHS: Nigeria Demographic Health Survey, NPC: National Population Commission, NMSP: National Malaria Strategic Plan, WHO: World Health Organization, LLIN: Long-lasting insecticide nets.

\section{Declarations}

\section{Acknowledgments}

We would like to thank ICF International for granting access to the DHS dataset. We also like to thank Bridgette Wellington, Cameron Taylor, Ikenna Onoh, and Usman Adekanye for supporting the design of the study and analysis of the DHS dataset. Special thanks to the African Field Epidemiology Network for their intellectual contributions towards improving the manuscript.

\section{Authors' contributions}

ME and MKA were involved in the design of the study, analysis, interpretation of findings, and drafted the manuscript. CDU, MSB, EB, and TD were involved in the interpretation of results and critical review of the manuscript. All the authors read and approved the final version of the manuscript.

\section{Funding}

The study did not require funding as it was secondary data analysis.

\section{Availability of data and materials}

The dataset used may be availed by the DHS program on justifiable request.

\section{Ethics Approval and Consent to participate}

The survey protocol was reviewed and approved by the National Health Research Ethics Committee of Nigeria (NHREC) and the ICF Institutional Review Board. Informed consent for the survey was obtained from each respondent at the beginning of every individual interview. Confidentiality was maintained by the survey interviewers as records were serialized and did not disclose the identity of respondents.

Approval for use of Nigeria's DHS 2018 data set for secondary analysis was granted on $18^{\text {th }}$ May 2020 by ICF International. The accessed data set was kept on a passworded computer.

\section{Consent for publication}

Not applicable

\section{Competing interests}

The authors declare that they have no competing interest

\section{Author Details}


${ }^{1}$ Nigeria Field Epidemiology and Laboratory Training Program, Abuja, Nigeria. ${ }^{2}$ Department of Veterinary and Pest control services, Federal Ministry of Agriculture and Rural Development, Abuja, Nigeria.

${ }^{3}$ Department of Community Medicine, Alex Ekwueme Federal University Teaching Hospital, Abakaliki, Ebonyi State, Nigeria. ${ }^{4}$ Department of Epidemiology and Medical Statistics, College of Medicine, University of Ibadan, Ibadan, Nigeria. ${ }^{5}$ Department of Community Medicine, Ahmadu Bello University, Zaria, Kaduna State, Nigeria.

\section{References}

1. WHO. World Malaria Report 2020. 2020;

2. Worldwide M. Nigeria Malaria Fact Sheet. 2010;

3. Kilian A, Lawford H, Ujuju CN, Abeku TA, Nwokolo E, Okoh F, et al. The impact of behaviour change communication on the use of insecticide treated nets: a secondary analysis of ten post - campaign surveys from Nigeria. Malar J. 2016;1-16.

4. Gone T, Lemango F, Eliso E, Yohannes S, Yohannes T. The association between malaria and malnutrition among under-five children in Shashogo District, Southern Ethiopia: a case-control study. Infect Dis Poverty [Internet]. 2017;4-11. Available from: http://dx.doi.org/10.1186/s40249-016-0221-y

5. Gari T, Loha E, Deressa W, Solomon T, Lindtj B. Malaria increased the risk of stunting and wasting among young children in Ethiopia: Results of a cohort study. 2018;(Ci):1-16.

6. Aderibigbe SA, Olatona FA, Sogunro O, Alawode G, Babatunde OA, Olarinoye AO, et al. Ownership and utilisation of long lasting insecticide treated nets following free distribution campaign in South West Nigeria. 2014;8688:1-6.

7. Indicator M. Malaria Indicator Survey (MIS) 2015. 2015;

8. Survey ND and H. Nigeria. 2018.

9. Pryce J, Richardson M, Lengeler C, Pryce J, Richardson M, Lengeler C. Insecticide-treated nets for preventing malaria ( Review ). 2018;

10. NPC. Census results of the 2006, Abuja, Nigeria. 2007.

11. Israel OK, Fawole OI, Adebowale AS, Ajayi IO, Yusuf OB, Oladimeji A, et al. Caregivers ' knowledge and utilization of long - lasting insecticidal nets among under - five children in Osun State, Southwest , Nigeria. Malar J [Internet]. 2018;1-9. Available from: https://doi.org/10.1186/s12936-018-2383-5

12. Iwuafor AA, Egwuatu CC, Nnachi AU, Ita IO, Ogban GI, Akujobi CN, et al. Malaria Parasitaemia and the use of insecticide-treated nets ( INTs) for malaria control amongst under-5 year old children in 
Calabar , Nigeria. BMC Infect Dis [Internet]. 2016;1-12. Available from: http://dx.doi.org/10.1186/s12879016-1459-5

13. Afolabi BM, Sofola OT, Fatunmbi BS, Komakech W, Okoh F, Saliu O, et al. Household possession, use and non-use of treated or untreated mosquito nets in two ecologically diverse regions of Nigeria Niger Delta and Sahel Savannah. Malar J. 2009;8(1):1-10.

14. Thar Min K, Maung Maung T, Minn Oo M, Oo T, Lin Z, Thi A, et al. Utilization of insecticide-treated bed nets and care-seeking for fever and its associated socio-demographic and geographical factors among under-five children in different regions: evidence from the Myanmar Demographic and Health Survey, 2015-2016. Malar J [Internet]. 2020 [cited 2021 May 9];19:7. Available from: https://doi.org/10.1186/s12936-019-3088-0

15. Nkoka O, Chipeta MS, Chuang YC, Fergus D, Chuang KY. A comparative study of the prevalence of and factors associated with insecticide - treated nets usage among children under 5 years of age in households that already own nets in Malawi. Malar J [Internet]. 2019;1-10. Available from: https://doi.org/10.1186/s12936-019-2667-4

16. Osuorah C, Ezeudu EC, Onah KS, Anyabolu TO. Household bed ownership and use among under 5 children in Nigeria. Res Rep Trop Med. 2013;4:15-27.

17. Admasie A, Zemba A, Paulos W. Insecticide-Treated Nets Utilization and Associated Factors among under-5 Years Old Children in Mirab-Abaya District, Gamo-Gofa Zone, Ethiopia. 2018;6(February):1-7.

18. Orji Lauretta Maria (Department of paediatrics, Federal Teaching Hospital, Abakaliki, Ebonyi State), Oyire Nnamdi Benson(Department of Paediatrics, Federal Teaching Hospital, Abakaliki), Chapp-Jumbo Assumpta (Department of Paediatrics, Abia State Teaching E. Perception and Utilization of insecticidetreated mosquito nets among caregivers of children in Abakaliki. Ann Afr Med. 2018;17(4).

19. Njau JD, Stephenson R, Menon M, Kachur SP, Mcfarland DA. Exploring the impact of targeted distribution of free bed nets on households bed net ownership , socio-economic disparities and childhood malaria infection rates: analysis of national malaria survey data from three sub-Saharan Africa countries. Malar J [Internet]. 2013;12(1):1. Available from: Malaria Journal

20. Inungu JN, Ankiba N, Minelli M, Mumford V, Bolekela D, Mukoso B, et al. Use of Insecticide-Treated Mosquito Net among Pregnant Women and Guardians of Children under Five in the Democratic Republic of the Congo. 2017;2017.

21. Millar KR, Mccutcheon J, Coakley EH, Brieger W, Ibrahim MA, Mohammed Z, et al. Patterns and predictors of malaria care-seeking, diagnostic testing, and artemisinin-based combination therapy for children under five with fever in Northern Nigeria : a cross-sectional study. 2014;1-12. 
22. Babalola OJ, Ajumobi O, Ajayi IO. Rural - urban disparities and factors associated with delayed care - seeking and testing for malaria before medication use by mothers of under - five children , Igabi LGA , Kaduna Nigeria. Malar J [Internet]. 2020;1-11. Available from: https://doi.org/10.1186/s12936-02003371-w

23. Cassy A, Saifodine A, Candrinho B, Martins R. Care - seeking behaviour and treatment practices for malaria in children under 5 years in Mozambique: a secondary analysis of 2011 DHS and 2015 IMASIDA datasets. Malar J [Internet]. 2019;1-10. Available from: https://doi.org/10.1186/s12936-019-2751-9

24. Plan S. Strategic Plan 2014 - 2020. 2020;

25. Mitiku I, Assefa A. Caregivers ' perception of malaria and treatment - seeking behaviour for under five children in Mandura District, West Ethiopia: a cross - sectional study. Malar J. 2017;1-10.

26. Negatou M, Ouedraogo M, Donnen P, Paul E, Samadoulougou S. Care-Seeking for Fever for Children Under the Age of Five Before and After the Free Healthcare Initiative in Burkina Faso: Evidence from Three Population-Based Surveys. 2021;2065-77.

\section{Figures}

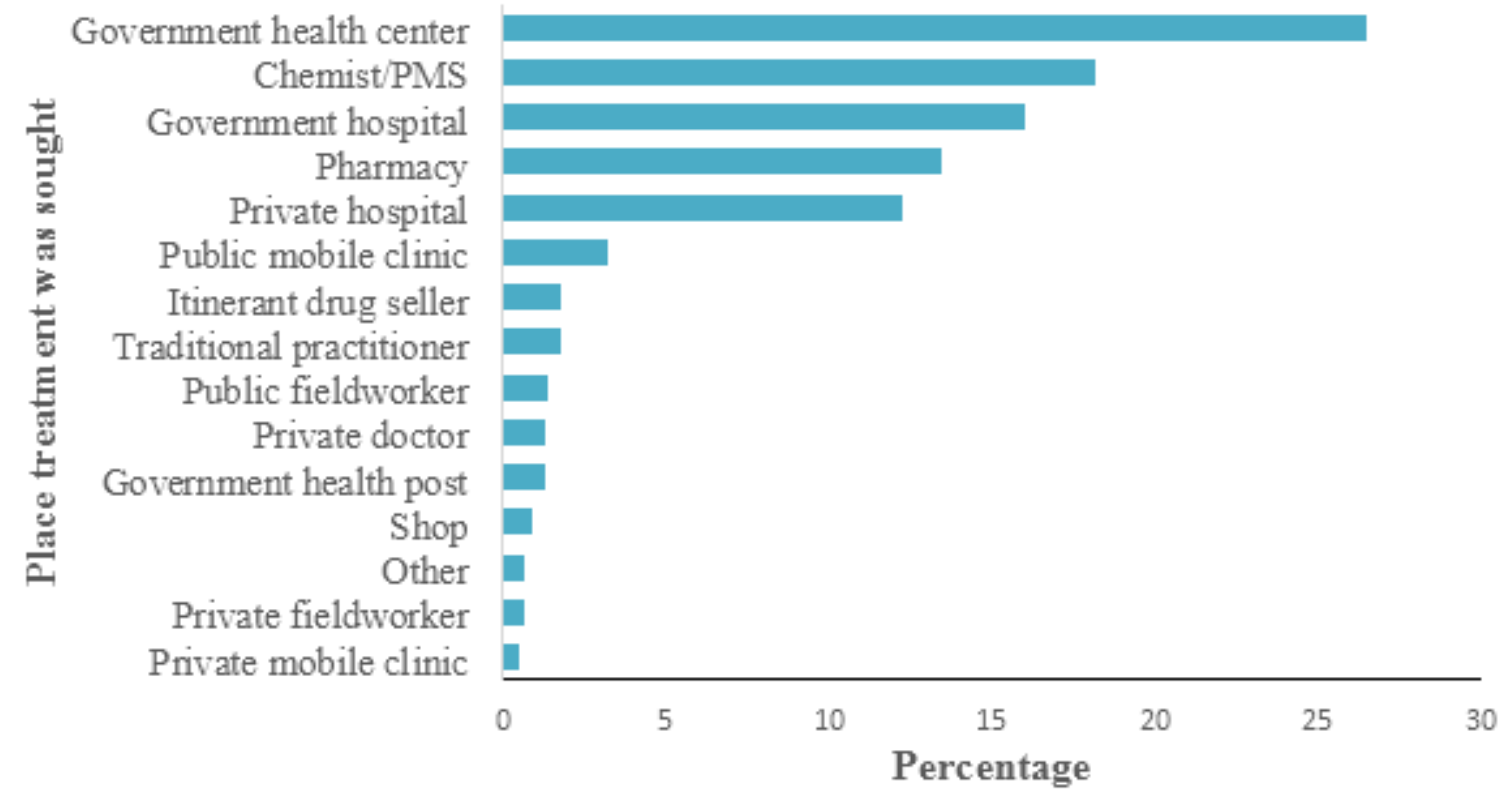

\section{Figure 1}

Place where treatment of fever for children U5 was first sought 